\title{
THE PREVALENCE OF OBESITY STIGMATIZATION AMONG PRIVATE UNIVERSITY STUDENTS IN SHAH ALAM, MALAYSIA
}

\author{
Afiqah Rajib, Khin Hla Hla Thein*, Hasanain Faisal Ghazi \& Tiba Nezar Hasan \\ International Medical School, Management \& Science University, Selangor, Malaysia. \\ *Corresponding Author: khin_hla@msu.edu.my
}

\begin{abstract}
Introduction: Stigma and discrimination toward obese person are pervasive and have created various consequences for their psychological and physical health. Various studies in American society showed obese person are negatively stereotyped. The aim of the study is to identifying the perceptions of students towards the obesity stigmatisation. Methods: This study used 300 students who will answer a self-administered questionnaire on obese stigmatization. A total of 150 male $(50 \%)$ and 150 female $(50 \%)$ are targeted in this research. The study used a convenience sampling method to collect the data using self-administered questionnaires Result: The findings showed that a total of $51 \%$ of the students had negative attitude towards obesity. There was a significant correlation between attitude towards obesity stigmatization and eating disorder with $(r=0.201)$ and between attitude and body image with $(r$ $=0.245$ ) Conclusion: $\mathrm{A}$ total of $51 \%$ of the students had negative attitude towards obesity. More health promotion and awareness on a balance diet and to understand the perspective view towards obesity stigmatization.
\end{abstract}

Keywords: Obesity, stigmatization, attitudes, emotional eating, body image. 


\section{Introduction}

The increase of overweight and obesity cases in Malaysia concern the society because of the effect of this increase in weight on many of chronic illnesses such as diabetes, heart disease, arthritis and stroke. Meanwhile, one study done in Malaysia found that obese participant perceived themselves to have a normal weight and thus had no determination of reducing their weight (Chang et al., 2009). Furthermore, in addition to the obesity effect on physical health, it has psychological affect due to stigma and discrimination toward those suffering from it. Many studies in American society showed obese person are negatively stereotyped. The overweight and obese individuals are said to be lazy, weak intention, unsuccessful, less intelligent, lack of selfdiscipline, not capable of following weight reduction treatment and many other negative stereotypes. This disease stigma arises when the society blamed those with obesity for their illnesses because they are considered as immoral unclean or lazy. Furthermore, society regularly regards obese person not as innocent victims but as architects of their own ill health, personally responsible for their weight problems because of being inactive and eating too much. The stigma associated with obesity is a major psychological \& socioeconomic burden for affected persons \& their families (Puhl \& Heuer, 2010). Other than that, obesity stigma involves actions against people with obesity that can cause exclusion and marginalization and lead to inequities and individuals who are overweight or obese reported a significant history of being threatened by stereotypes related to weight (Carels et al., 2013 \& WHO, 2019).
In the knowledge and information era we live in, we understand that the rate of obesity has been growing around the world and the obesity stigma is a result of devaluing the physical attributes which are related to being overweight. People tend to have negative \& stigmatizing attitudes toward obesity including obese persons themselves (Levit et al., 2018). In addition, a study in Germany state that there is a large number of students have negative attitude towards those overweight people compared to those individual with normal weight in which it is consistent with the common stereotype that overweight individuals have less self-discipline and inactive physically (Pantenburg et al., 2012). On the other hand, the BMI is an approximate measure of total body fat and the BMI for obesity are divided into 3 categories which include the obesity class I, obesity class II and obesity class III. The obesity class I are in range of $30-34.9$. The obesity class II are in range of $35-39.9$. Then, the obesity class III are said to be 40 above (Marengo, 2018). On the contrary, food and beverage television advertisements have been found to play a substantial role in marketing the nutrition less food among several sections of the population, contributing to the global obesity and pandemics (Tempels et al., 2017). Moreover, eating restraint is often related to weight loss in behavioural treatments and is suggested to be a risk factor for the development of eating disorders. Besides that, the prevailing suggested definition of binge eating including consumption of large quantities of food without being in control of this behaviour (Elfhag \& Rossner, 2005). At the same time, body disapproval and low satisfaction about body image has been identified as a psychological effect of obesity that is usually 
associated and lead to disordered eating, poor self-esteem and depression (Weinberger et al., 2016). Therefore, The aim of the study is to identifying the perceptions of students towards the obesity stigmatisation.

\section{Methods}

A cross-sectional study was conducted among 300 private university in Shah Alam. Selfadministered questionnaires were used to collect data. students were age between 18 35 years old in which it is a range for a young adult and the study was conducted from February 2019 to April 2019. The questionnaire given are to access the prevalence attitude toward obesity stigma and demographic data of the young adults. Also, to access the attitude with obesity stigmatization, attitude with eating disorder and attitude with body image disturbance. In addition, the questionnaire are given to 150 male students and 150 female students by using a non-probability quota sampling method.

The questionnaires consist of 4 parts, part $\mathrm{A}$ about socio demographic background of the respondents. Part $B$ regarding attitude towards obesity that adopted from Gipson et al., 2005. The responses of participants were numbered in order of preference from 1 to 6 (strongly disagree to strongly agree). Part $\mathrm{C}$ about eating disorder adopted from Fairburn \& Berlin, 1994, the participants' responses were numbered in order of preference from 1 to 7 (no days to everyday). Part $D$ for body image disturbance adopted from (Fairburn \& Berlin, 1994) the participants' responses were numbered in order of preference from 1 to 7 (not at all to markedly) Data was analysed using SPSS software version 23.0. The significance value for the test will be $p$-value of $<0.05$. Moreover, the prevalence of attitude of obesity stigmatization are expressed by using frequency $(n)$ and percentages (\%) and Pearson correction test was used.

All respondents signed the consent form before answering the questionnaires and ethical approval obtained from management and science university ethics committee.

\section{Results}

Three hundred participants were included in the analyses which showed 50\% (150) male and $50 \%$ (150) female participated in this study. Majority of the students involved were from Degree program which is $62.7 \%$ (188) followed by $31.3 \%(94)$ from diploma program and $6 \%$ (18) from foundation program. In addition, $30 \%$ (90) were from IMS, $8.3 \%$ (25) were from SESS, 19\% (57) were from FISE, 25.7\% (77) were from FBMP, 6.7\% (20) were from FHLS, $4.3 \%$ (13) were from $\mathrm{SPH}, 1 \%$ (3) were from PGC and 5\% (15) were from SHCA. Meanwhile, the BMI for 300 students were founded to be $90.7 \%$ (272) were normal or underweight, $6.0 \%$ (18) were in obesity class I, $2.7 \%$ (8) were in obesity class II \& $0.7 \%$ (2) were in obesity class III.

Based on descriptive statistic of attitudes towards obesity, the statement of 'Most obese people are more self-conscious than other people' shows the highest mean of 4.16 refers to strongly agree and SD of 1.000. In addition, the eating disorder showed 'Have you had a strong desire to lose weight' with the highest mean of 4.04 refers to $13-15$ days and SD of 2.895. Then, the body image disturbance showed 'How dissatisfied have you been with your weight?' with the highest mean of 3.52 refers to moderately agree and SD of 1.999 . Besides that, Table 1 shows the prevalence of 
attitude towards obesity among young adults in Management \& Science University. In addition, the negative attitude towards obesity was $51.0 \%$ (153) which was slightly higher than positive attitude towards obesity that is $49 \%$ (147).

Table 1: Prevalence of attitude towards
obesity
\begin{tabular}{|l|r|r|}
\hline \multicolumn{1}{|l|}{$(\boldsymbol{n})$} & $(\%)$ \\
\hline $\begin{array}{l}\text { Negative } \\
\text { attitude } \\
\text { towards } \\
\text { obesity }\end{array}$ & 153 & $51 \%$ \\
\hline $\begin{array}{l}\text { Positive } \\
\text { attitude } \\
\text { towards } \\
\text { obesity }\end{array}$ & 147 & $49 \%$ \\
\hline Total & 300 & $100 \%$ \\
\hline
\end{tabular}

To test the hypotheses of the study, a Pearson correlation test was used to identify relationship between attitude and eating disorder shown in Table 2 and attitudes and body image shown in shows that $r=0.201$ and $p<0.05$ which showed that there is a positive relationship between attitudes towards obesity and eating disorder. Meanwhile, Attitude \& body image disturbance showed $r=0.245$ and $p<0.05$ which showed that there is a positive relationship between attitudes towards obesity and body image.

Table 2: Correlation between attitude with eating disorder \& body image disturbance

\begin{tabular}{|l|c|c|}
\hline \multicolumn{1}{|c|}{ Variables } & Correlation & P Value \\
\hline $\begin{array}{l}\text { Attitude \& } \\
\text { eating } \\
\text { disorder }\end{array}$ & $r=0.201$ & 0.03 \\
\hline $\begin{array}{l}\text { Attitude \& } \\
\text { body image } \\
\text { disturbance }\end{array}$ & $r=0.245$ & 0.04 \\
\hline
\end{tabular}

\section{Discussion}

The main findings of this study that $51 \%$ of respondents had negative attitude towards obesity. The result has revealed that the respondents were concerned about the manifestations of overweight or obesity which are considered as a moral failure. The result also showed the prevalence of attitudes towards obesity showed negative attitude are slightly higher compare to the positive attitude towards obesity. These conclude that the respondents are said to disagree on the statements of attitude towards obesity. However, majority of the respondent are strongly agree with one statement such as 'Most obese people are more self-conscious than other people'. Furthermore, a study of attitudes towards obesity conducted in India showed peers have more negative than positive attitudes towards obesity (Rashmi \& Jaswal, 2011). This study supported the result of the prevalence of attitude towards obesity of the past study by these two scholars. Moreover, the negative attitudes as a blame were associated with the belief that individuals are responsible for obesity (Luck-Sikorski \& Riedel-Heller, 2017). Other than that, the age 18 - 25-year-old reported more negative attitudes towards obese people (Flint et al., 2015). At the same time, many studies showed that obese individuals suffer from serious physical health consequences such as diabetes, cardiovascular problem, hypertension or dyslipidaemia in addition to suffering from social problems and restrictions due to negative attitudes and discrimination towards them (Stein et al., 2014).

Moreover, this study also found that there is a relationship between attitudes towards obesity 
and eating disorder. The eating disorders are diseases in which the people have severe imbalance in their eating behaviours and related emotions and thoughts. People having such eating disorders typically become preoccupied with food and their body weight. In the Diagnostic and Statistical Manual of Mental Disorders 5, the eating disorders section was renamed 'Feeding and Eating Disorders' and specified into three eating disorders which are anorexia nervosa, bulimia nervosa and binge eating disorder and three common feeding disorders such as pica, rumination disorder and avoidant or restrictive food disorder. Common risk factors of obesity and eating disorders can be classified into three levels according to the Social Ecological Model such as individual that includes sex, age and weight status. Then, social like as media, weight teasing and ideal beauty pattern, in addition to psychological such as self-esteem and body satisfaction (Leme et al., 2018). The consistent of this theory shows that the obese people who have been teased or victimized about their weight are more vulnerable to binge eating patterns and those who internalize weight-based stereotypes may be at heightened risk of engaging in binge eating behaviour (Puhl et al., 2010). Other than that, a previous study showed that a greater stigma is related with eating disorders (Harrison \& Bertrand, 2016). Apart from that, a study in Australia between the years of 1995 to 2015 found that there were significant rises in the prevalence of obesity and eating disorder behaviours independently, however, the highest increases were in the prevalence of individuals with obesity and comorbid binge eating or very strict dieting. Then, it is found that symptoms of depression \& low self-esteem in dieters were important elements increasing the risk of binge eating. Meanwhile, the dieting can be associated with these negative consequences (Luz et. al., 2018). In addition, these related articles supported the result of eating disorder statement in the current study in which the most of the young adults strongly agree with a strong desire to lose weight.

Along similar argument, the study also showed there is a relationship between attitudes towards obesity and body image disturbance. The result revealed that participants were concerned about the body image appearance especially pertaining to ideal weight with a perfect physical body shape. Besides that, the body dissatisfaction has been identified as a psychological correlate of obesity that is related to disordered eating, poor selfesteem and depression (Weinberger et al., 2016). Besides that, there are also concern for the four elements to a body image which include how you see your body, how you feel about your body, how you think about your body and what you do as a result of all of the clarification. Moreover, the body image has implications on mental health such as selfesteem, anxiety, depression and selfconfidence and eating disorders. Also, the physical illness such as obesity play a role in body image (Pakki \& Sathiyaseelan, 2018). Other than that, the weight bias and obesity stigma lead to low self-acceptance of body image and lower the self-esteem and selfconfidence, in addition to feelings of worthlessness and loneliness. Also, it leads to general anxiety and depression in people who are overweight and obese. In addition, weight bias and obesity stigma have a negative influence on body mass, as they may provoke binge eating and reduce the motivation to lose weight. This negative effect results from a low 
self-acceptance of body mass which leads to eat more in response to this negative emotion. Thus, the emotional outcome associated with body mass image and acceptance may decline the general well-being and hinder weight loss in overweight or obese individuals (Regwelski et al., 2019).

\section{Conclusion}

A total of $51 \%$ of the students had negative attitude towards obesity. More health promotion and awareness on a balance diet and to understand the perspective view towards obesity stigmatization. The discriminated individuals may be emotionally and psychologically supported by various members of the society. Furthermore, the understanding of attitudes towards obese people may motivate young adults to adopt healthier living and reducing negative attitudes as well as beliefs towards obesity stigmatization. This could be a proactive starting point in our battle against obesity stigmatization which has been a public health concern. The stigma is also a major barrier to psychological burden affecting overweight and obese persons. Hence, stigmatization needs to be eliminated.

\section{References}

Carels,RA. Burmeister,J. Oehlhof, MW et al. 2013. "Internalized weight bias: ratings of the self, normal weight, and obese individuals and psychological maladjustment," Journal of Behavioral Medicine, 36(1): 86-94.

Chang C. T., Chang K. H. \& Cheah W. L., 2009. Adults' perceptions of being overweight or obese: a focus group study. Asia Pacific Journal of Clinical Nutrition. 18(2): $257-264$

Elfhag K. \& Rössner S., 2005. Who succeeds in maintaining weight loss? A conceptual review of factors associated with weight loss maintenance and weight regain. Obesity reviews. 6: 67-85

Fairburn C. G. \& Beglin S. J., 1994. Assessment of eating disorders: interview or self-report questionnaire?. International Journal of Eating Disorders. 16(4): $363-70$

Flint S. W., Čadek M., Codreanu S. C., Ivić V., Zomer C. \& Gomoiu A., 2018. Obesity Discrimination in the Recruitment Process: "You're Not Hired!". Frontiers in Psychology. 7(647): 1 - 9

Gipson G. W., Reese S., Vieweg V., Anum E. A., Pandurangi A. K., Olbrisch M. E., Sood B., Silverman J. J., Petersburg \& Richmond, 2005. Body Image and Attitude toward Obesity in an Historically Black University. Journal of National Medical Association. 97(2): 225 - 237

Harrison A. \& Bertrand S., 2016. To what Extent do the Public Need Educating about Eating Disorder?. Journal Obesity \& Eating Disorder. 2(26): 1 - 8

Leme A. C. B., Thompson D., Dunker K. L. L., Nickles T., Philippi S. T., Lopez T., Vézina-Im L-A. \& Baranowski T., 2018. Obesity and eating disorders in integrative prevention programmes for adolescents: protocol for a systematic review and meta-analysis. BMJ Open. 8: $1-6$

Luck-Sikorski C., Riedel-Heller S. G., Phelan J. C., 2018. Changing attitudes towards obesity - results from a survey experiment. BMC Public Health. 17(1): 373

Levit T., Lavack A. M. \& Watson L., 2018. Obesity and Stigmatization at Work. Stigmas, Work and Organizations. New York: Palgrave Macmillan. July: 11-34

Luz F. Q. D., Hay P., Touyz S. \& Sainsbury A., 2018. Obesity with Comorbid Eating Disorders: Associated Health Risks and Treatment Approaches. Nutrients. 10(829): $1-9$

Marengo K., 2018. BMI calculators and charts. Retrieved on $22^{\text {nd }}$ May 2019. https://www.medicalnewstoday.com/arti cles/323586.php

Pakki S. S. \& Sathiyaseelan A., 2018. Issues Related to Body Image in Young Adult Women. Saudi Journal Humanities Social Science. 3(2): $250-254$

Pantenburg B., Sikorski C., Luppa M., Schomerus G., König H-H., Werner P. \& Riedel-Heller S. G., 2012. Medical Students' Attitudes towards Overweight and Obesity. PLOS ONE. 7(11): $1-8$ 
Puhl R. M., Masheb R. M., White M. A. \& Grilo C. M., 2010. Attitudes toward obesity in obese persons: A matched comparison of obese women with and without binge eating. Eat Weight Disorder. 15(1): e173-e179

Puhl R. M. \& Heuer C. A., 2010. Obisity stigma: Important Considerations for Public Health. American Journal Public Health. 100(6): 1019 - 1028

Rashmi \& Jaswal S., 2011. Attitude of Parents, Peers and Teachers towards Obese Teenagers. Journal Psychology. 2(1): 45 $-51$

Regwelski M, Ewa Lange, Dominika Gła bska and Dominika Guzek. 2019. Analysis of the Influence of Age, BMI, and WHtR on Body Mass Acceptance, Attitudes, and Motivation towards Body Mass Reduction in Overweight and Obese Caucasian Women, Nutrients 2019, 11(3), 542; https://doi.org/10.3390/nu110305 42

Stein J., Luppa M., Ruzanska U., Sikorski C., König H. H., Riedel-Heller S. G., 2014. Measuring Negative Attitudes towards Overweight and Obesity in the German Population - Psychometric Properties and Reference Values for the German Short Version of the Fat Phobia Scale (FPS). PLOS ONE. 9(12): $1-18$

Tempels, Verweij T. \& Blok M. V., 2017. Big Food's Ambivalence: Seeking Profit and Responsibility for Health. American Journal of Public Health. 107(3): 402 406

Weinberger N. A., Kersting A., Riedel-Heller S. G. \& Luck-Sikorski C., 2016. Body Dissatisfaction in Individuals with Obesity Compared to Normal-Weight Individuals: A Systematic Review and Meta-Analysis. Obese Facts. 9:424-441

World Health Organization, 2019. Weight bias and obesity stigma: considerations for the WHO European Region. Retrieved on $22^{\text {nd }} \quad$ May 2019. http://www.euro.who.int/_data/assets/p df_file/0017/351026/WeightBias.pdf 